\title{
DIFFUSION-LIMITED REACTIVE WETTING: SPREADING OF Cu-Sn-Ti ALLOYS ON VITREOUS CARBON
}

\author{
Olivier Dezellus, Fiqiri Hodaj, Andreas Mortensen ${ }^{1}$ and Nicolas Eustathopoulos \\ L.T.P.C.M., URA-CNRS 29, Institut National Polytechnique de Grenoble, F-38402, St Martin- \\ d'Hères, Cedex France ${ }^{1}$ Department of Materials, EPFL (Swiss Federal Institute of Technology in \\ Lausanne), CH-1015, Lausanne, Switzerland
}

(Received October 26, 2000)

(Accepted in revised form January 17, 2001)

Keywords: Reactive wetting; Interfaces; Contact angle; Diffusion; Spreading

\section{$\underline{\text { Introduction }}$}

Wetting of a solid by a liquid can be significantly improved by addition to the liquid of appropriate alloying elements which, by reaction with the solid, cause the formation of an interfacial layer of a compound which is better wetted by the liquid than the original unreacted solid surface. Titanium is a frequently used such alloying addition for wetting of carbon-containing substrates: reaction then leads to the formation of $\mathrm{TiC}$, which by virtue of its partly metallic character is relatively well wetted by many metals and alloys $[1,2]$.

When wetting is promoted by interfacial reaction, the rate at which the liquid spreads over the solid substrate is controlled by the rate at which the well-wetted interfacial reaction product can be formed along the liquid/solid/atmosphere triple line. If this interfacial reaction involves a reactive alloy addition to the liquid, the rate of spreading can be limited by two possible phenomena [3]:

(i) local reaction kinetics at the triple line, leading to constant spreading rates, or

(ii) the rate of supply of reactant from the drop bulk to the triple line, itself generally limited by the rate of diffusion of solute through the liquid, leading to time-dependent spreading rates.

A simplified analysis of diffusion-limited reactive spreading [4], based on the assumption that the interfacial reaction is strictly localised at the triple line, has led to the conclusion that the velocity of a sessile drop triple line $\mathrm{dR} / \mathrm{dt}$ (where $\mathrm{R}$ is the radius of the drop base and $\mathrm{t}$ is time) varies in direct linear proportion to the instantaneous contact angle $\theta$ :

$$
\frac{\mathrm{dR}}{\mathrm{dt}}=\frac{2 \mathrm{DF}_{(\mathrm{t})}}{\mathrm{en}_{\mathrm{v}}}\left(\mathrm{C}_{\mathrm{o}}-\mathrm{C}_{\mathrm{e}}\right) \theta,
$$

otherwise exhibiting no significant explicit time-dependence. In Eq.(1), D is the diffusion coefficient in the liquid phase, $\mathrm{n}_{\mathrm{v}}$ is the number of moles of reactive solute per unit volume of the reaction product, $\mathrm{e}$ is the reaction product thickness at the triple line, $\mathrm{C}_{\mathrm{o}}$ is the nominal (far-field) drop reactive solute concentration, $\mathrm{C}_{\mathrm{e}}$ is the concentration of reactive solute in equilibrium with the reaction product (such that $\mathrm{C}=\mathrm{C}_{\mathrm{e}}$ at the triple line), and $\mathrm{F}_{(\mathrm{t})}$ is a function of time $\mathrm{t}$ which varies very little, and can thus be considered constant with a value near 0,04 in usual sessile drop experiments [4]. 


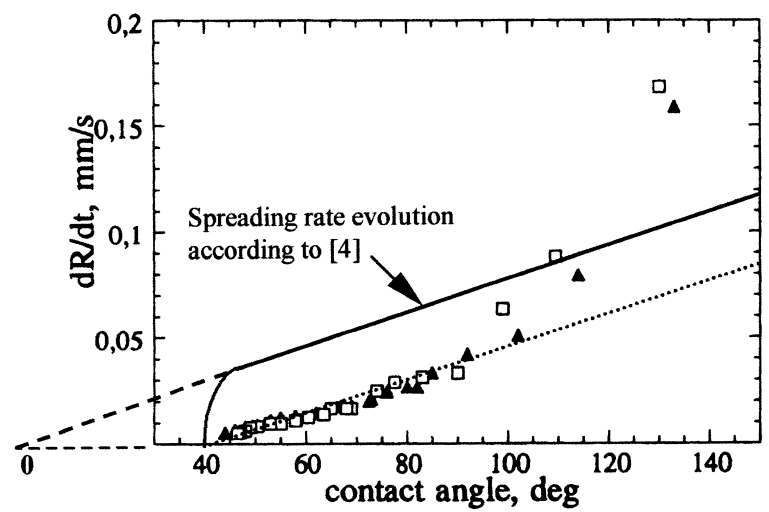

Figure 1. Experimental triple line velocity as a function of instantaneous contact angle $\theta$ for $\mathrm{Cu}-1$ at.\% $\mathrm{Cr}$ on vitreous carbon at $1150^{\circ} \mathrm{C}[5]$ and spreading rate according to Eq. (1), Ref. [4].

This relation was compared with spreading kinetics measured for $\mathrm{Cu}-\mathrm{Cr}$ alloys sessile drops on vitreous carbon (Fig. 1), which spread by formation of chromium carbide along the liquid/solid interface [5]. This comparison confirmed several of the predictions of the above analysis: the spreading rate is indeed found to be directly related to $\theta$, and to vary linearly with the drop nominal solute concentration $\mathrm{C}_{\mathrm{o}}$, confirming that spreading is indeed governed by solute transport for this system. Also, it was found that for $\theta<90^{\circ}, \mathrm{dR} / \mathrm{dt}$ does vary linearly with $\theta$; however, there are two discrepancies between data and theory for this system:

(i) for $\theta>90^{\circ}$, there is an upward deviation in the spreading rate from the linear relation observed at lower angles, and

(ii) for $\theta<90^{\circ}$, the intercept of the line of $\mathrm{dR} / \mathrm{dt}$ versus $\theta$ with the $\theta$ axis was not at the origin $(\theta=$ $0)$, but rather near the final equilibrium contact angle $\theta_{\mathrm{e}}$, of about $40^{\circ}$.

This paper is focused on the second discrepancy. This discrepancy was attributed to the presence of continuing drop/substrate chemical reaction behind the triple line [5]. Such reaction causes added solute to be consumed along the liquid/solid interface, in turn reducing, by diversion, the total flux of solute which reaches the triple line from the drop bulk. This interpretation was in particular reinforced by the fact that final measured chromium carbide interfacial reaction layers were relatively thick in the $\mathrm{Cu}-\mathrm{Cr} / \mathrm{C}$ system (several micrometers), and by the observation that the final reaction layer thickness increases significantly in this system with the total liquid/solid contact time, which suggests continued reaction after wetting.

A test of this interpretation could be provided by observation of a system for which the reaction layer is sufficiently impervious for the liquid/solid interaction to be effectively stopped behind the triple line. In what follows we present results for the $\mathrm{Cu}-\mathrm{Sn}-\mathrm{Ti} / \mathrm{C}_{\mathrm{v}}$ system, which satisfies this criterion. Indeed, at temperatures close to $1100^{\circ} \mathrm{C}$ the diffusion coefficient of carbon in solid $\mathrm{TiC}$, which is the reaction product in the above system, is 1-2 orders of magnitude lower than in chromium carbide [6,7].

\section{Experimental Procedures}

A substrate of vitreous carbon (V25 vitreous carbon, heat treated at $2773 \mathrm{~K}$ and featuring no open porosity, provided by Le Carbone-Lorraine, France) was mechanically polished to a $1 \mu \mathrm{m}$ diamond 


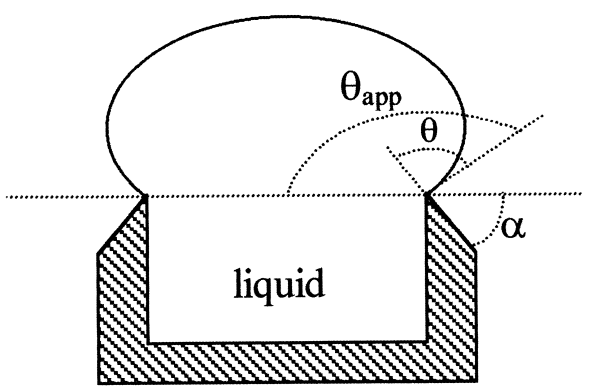

Figure 2. Principle of a large-drop experiment after Naidich et al. [2]. The use of a sharp-edged cup leads to an apparent contact angle $\theta_{\text {app }}=\theta+\alpha$ where $\theta$ is the true contact angle of liquid on the cup material.

paste. Height variations along the polished substrate surface were measured to be of amplitude between 1 and $2 \mathrm{~nm}$ and wavelength between 10 and $20 \mu \mathrm{m}$; the surface roughness of these substrates is thus sufficiently low not to influence wetting angle data. The metal drops were prepared from $99.999 \%$ pure copper and tin, and $99.7 \%$ purity titanium by alloy formation upon melting of elemental metals. The composition investigated is $\mathrm{Cu}-15$ at.\%Sn-3at.\% Ti.

The sessile drop experiments were conducted within a stainless steel cold wall furnace under a static purified helium atmosphere. The spreading process was filmed by a video-camera and recorded on videotape at a film speed of 25 frames per second. After the experiments, the measured contact angle, $\theta$, as well as the drop base radius, $\mathrm{R}$, were computed from the recorded drop profile with an accuracy of $\pm 2^{\circ}$ for $\theta$ and $\pm 2 \%$ for $\mathrm{R}$. The transferred drop technique, described in more detail in Ref [5], was used: in this technique, the drop is first formed and homogenized over an inert, non-wetted, substrate, and then raised until it contacts the carbon substrate from below. The drop then spreads, and detaches from the lower substrate; this causes an abrupt change in the contact angle during the experiment. Thereafter the drop remains suspended under the carbon substrate, over which it continues spreading until the equilibrium contact angle on the reaction product is attained.

A difficulty encountered in this study was to find a ceramic substrate that is at the same time non-reacting with the $\mathrm{Cu}-\mathrm{Sn}$-Ti alloy and poorly wetted by it (indeed, Ti-containing alloys react and wet most usual ceramics). To overcome this difficulty we used, instead of a flat substrate, an alumina support having the shape of a cup with sharp edges. This geometry makes it possible to produce apparent contact angles, $\theta_{\text {app }}$, that are much higher than the true contact angle $\theta$ of the melt on the substrate material (Fig. 2). This technique, used to measure the surface tension of metals and alloys $[8,9]$, led for the $\mathrm{Cu}-15 \mathrm{at} . \% \mathrm{Sn}-3 \mathrm{at} . \% \mathrm{Ti}$ alloy to values of $\theta_{\text {app }}$ exceeding ninety degrees, thus making it possible to transfer the drop upon contact with the carbon substrate.

After cooling of the drop, the interfacial reaction product chemistry and morphology were characterized by scanning electron microscopy.

A plot of the variations in time of the contact angle $\theta$ and the droplet base radius $\mathrm{R}$ for an experiment conducted at $1020^{\circ} \mathrm{C}$ is given in Fig. 3: it is seen that, aside from a perturbation observed at the moment of drop transfer and occurring around $50^{\circ}$, continuous curves are obtained. In agreement with [2], the $\mathrm{Cu}-15$ at.\% Sn-3at.\% Ti alloy wets very well vitreous carbon, the final contact angle being as low as $10^{\circ}$. Moreover, the $\mathrm{R}(\mathrm{t})$ curve displays a time-dependent spreading rate, indicating that local interfacial reaction kinetics do not govern the rate of spreading. Deriving from these data the triple line velocity $\mathrm{dR} / \mathrm{dt}$ and plotting this quantity as a function of the contact angle $\theta$, one obtains the curve in Fig. 4. As for the $\mathrm{Cu}-\mathrm{Cr} / \mathrm{Cv}$ couple, when $\theta<90^{\circ}$ the resulting data points lie roughly along a straight line; however, in the present system the resulting straight line through the data passes through the origin, the spreading rate falling abruptly to zero at the final, equilibrium, contact angle of the alloy on the reaction 


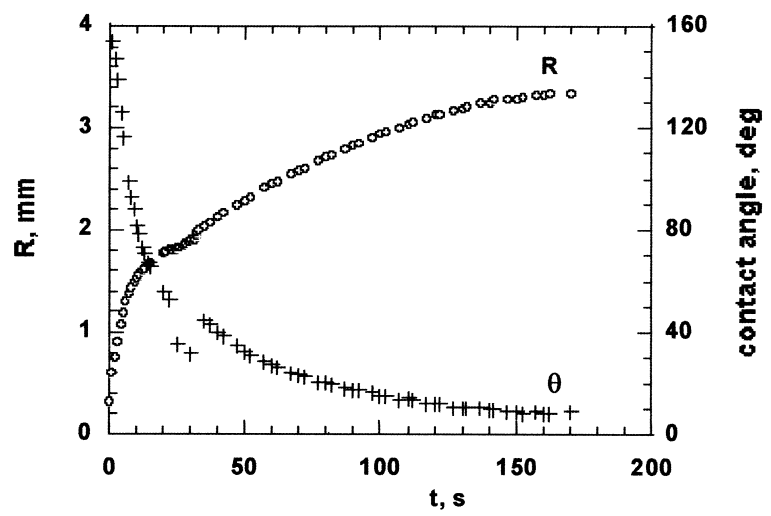

Figure 3. Contact radius $\mathrm{R}$ and contact angle $\theta$ as a function of time for $\mathrm{Cu}-15 \mathrm{at} . \% \mathrm{Sn}-3 \mathrm{at} . \% \mathrm{Ti}$ on vitreous carbon at $1020^{\circ} \mathrm{C}$. The perturbation at $\mathrm{t} \approx 25$ seconds is due to the detachment of the drop.

product, near $10^{\circ}$. Note that for $\theta>90^{\circ}$, the spreading rate deviates above the straight line in similar fashion to what was observed with the $\mathrm{Cu}-\mathrm{Cr} / \mathrm{C}$ system in Ref. [5].

A cross section of the interfacial region near the center of the drop is given in Fig. 5 (characterization of the interface near the triple line was unfortunately not possible because thermal stresses built-up during cooling of the drop caused interfacial failure, breaking up the drop and the substrate into many small fragments). It was found that the interface is composed of a thin and dense reaction layer of TiC, of average thickness slightly below $500 \mathrm{~nm}$.

A second experiment was performed with the same alloy at $1100^{\circ} \mathrm{C}$ instead of $1020^{\circ} \mathrm{C}$. The contact angle was again found to decrease from an initial value of $160^{\circ}$ to a final or equilibrium contact angle of about $10^{\circ}$; however, in this case, the detachment of the drop produced a strong perturbation of the $\mathrm{R}(\mathrm{t})$ curve, such that only the part of the curve after detachment can be used to plot the triple line velocity versus instantaneous contact angle curve, Fig. 6 . As for the data at $1020^{\circ} \mathrm{C}$, shown also in this figure for comparison, the data points lie on a straight line which passes through the origin. Unfortunately, mechanical failure of the drop along the interface during cooling to room temperature destroyed the interfacial reaction layer, precluding its microstructural characterization.

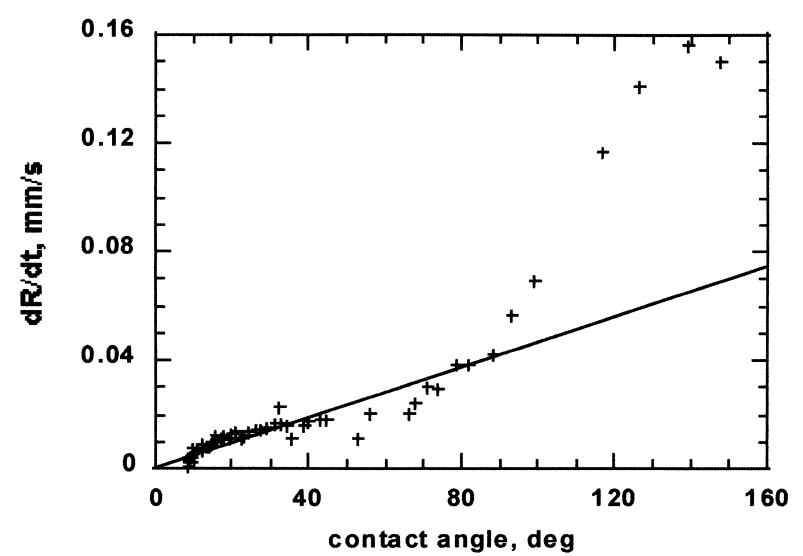

Figure 4. Triple line velocity as a function of instantaneous contact angle $\theta$ for $\mathrm{Cu}-15 \mathrm{at} . \% \mathrm{Sn}-3 \mathrm{at}$. $\mathrm{Ti}$ on vitreous carbon at $1020^{\circ} \mathrm{C}$. 


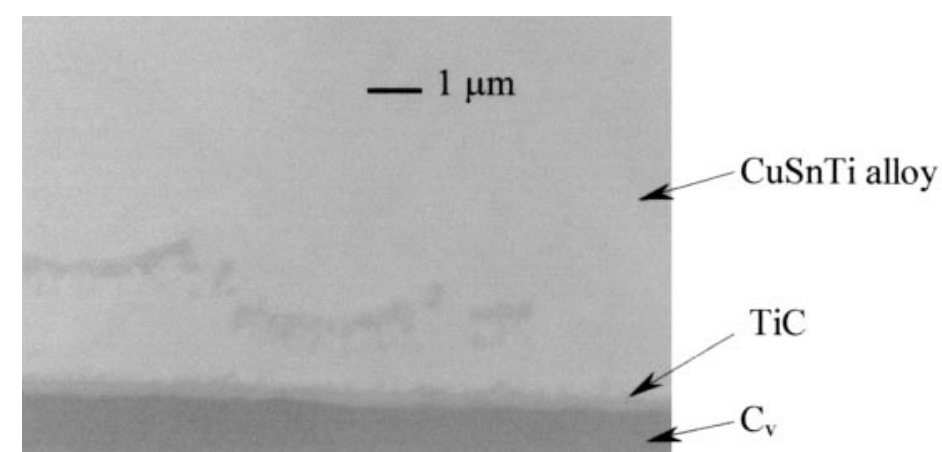

Figure 5. Micrograph of drop-substrate interface for $\mathrm{Cu}-15$ at. $\% \mathrm{Sn}-3$ at. $\% \mathrm{Ti}$ alloy on vitreous carbon at $1020^{\circ} \mathrm{C}$ showing titanium carbide formation.

\section{$\underline{\text { Discussion }}$}

Unlike copper-chromium alloys, $\mathrm{Cu}-15 \mathrm{at} . \% \mathrm{Sn}-3 \mathrm{at} \% \mathrm{Ti}$ thus displays the simple linear relationship between $\mathrm{dR} / \mathrm{dt}$ amd $\theta$ predicted by Eq. (1). The slope of the line through the data at $1020^{\circ} \mathrm{C}$ for $\theta<$ $90^{\circ}$ is $2.7 .10^{-5} \mathrm{~m} \cdot \mathrm{s}^{-1} \cdot(\text { radian })^{-1}$. Taking $\mathrm{n}_{\mathrm{v}}=8.26 .10^{4}$ moles $\cdot \mathrm{m}^{-3},\left(\mathrm{C}_{\mathrm{o}}-\mathrm{C}_{\mathrm{e}}\right) \approx \mathrm{C}_{\mathrm{o}}=1640$ moles $\cdot \mathrm{m}^{-3}$, and using an estimated value of $\mathrm{D} \approx 5 \cdot 10^{-9} \mathrm{~m}^{2} \cdot \mathrm{s}^{-1}$, this slope corresponds, according to Eq. (1), to a thickness e of the TiC reaction layer formed at the triple line of $300 \mathrm{~nm}$. This is close to the observed reaction layer thickness, found at $1020^{\circ} \mathrm{C}$ to be slightly below $500 \mathrm{~nm}$. The expected difference between e (the thickness of the reaction layer formed at the triple line during spreading and deduced from spreading kinetics using Eq. (1)) and its final value at the end of the experiment can be estimated knowing the diffusion coefficient of $\mathrm{C}$ in bulk $\mathrm{TiC}\left(\mathrm{D}_{\mathrm{C}}\right)$. This quantity is a function of stoechiometry of $\mathrm{TiC}_{\mathrm{y}}$ which in turn depends on the activity of $\mathrm{Ti}$ in the alloy, $\mathrm{a}_{\mathrm{Ti}}$. For $\mathrm{Cu}-15 \mathrm{at} \% \mathrm{Sn}$ 3at $\% \mathrm{Ti}, \mathrm{a}_{\mathrm{Ti}}=2.10^{-3}[10]$, corresponding to $\mathrm{y}=0.8[11]$, from which we deduce that $\mathrm{D}_{\mathrm{C}}=1.6 .10^{-17}$ $\mathrm{m}^{2} \cdot \mathrm{s}^{-1}$ at $1020^{\circ} \mathrm{C}$ and $9.7 .10^{-17} \mathrm{~m}^{2} \cdot \mathrm{s}^{-1}$ at $1100^{\circ} \mathrm{C}$ [6] (for $\mathrm{y}=1, \mathrm{D}_{\mathrm{C}}$ is lower, equalling 2.6.10 $\mathrm{m}^{2} . \mathrm{s}^{-1}$ at $\left.1020^{\circ} \mathrm{C}\right)$. It can then be estimated that during the time of spreading of the drop $(150 \mathrm{~s}$ at $1020^{\circ} \mathrm{C}$ and $50 \mathrm{~s}$ at $1100^{\circ} \mathrm{C}$ ), the reaction layer can only grow, starting from an initial thickness of 300 $\mathrm{nm}$, by only an additional 25 and $35 \mathrm{~nm}$ at the center of the drop/substrate interface, at 1020 and $1100^{\circ} \mathrm{C}$ respectively (and by less elsewhere since the time of contact is shorter). The data are, thus, fully consistent with the assumptions of Ref. [4] and reinforce the suggestion made in Ref. [5] that the

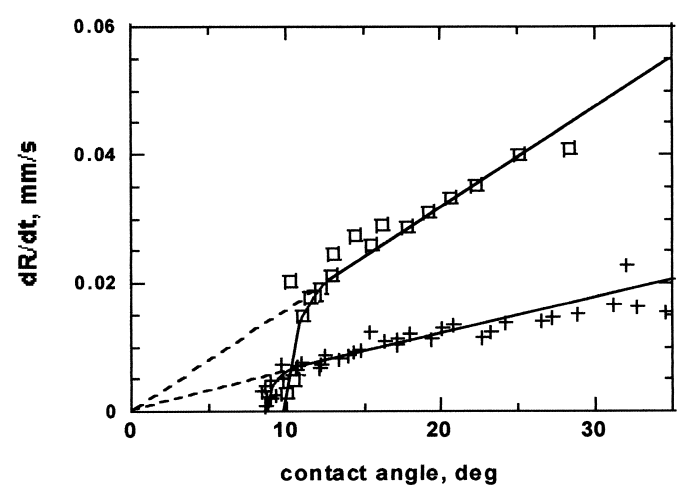

Figure 6. Triple line velocity as a function of instantaneous contact angle $\theta$ in the low contact angle range for $\mathrm{Cu}-15 \mathrm{at} \%$ Sn-3at.\% Ti on vitreous carbon at $1100^{\circ} \mathrm{C}(\square)$ and $1020^{\circ} \mathrm{C}(+)$. 


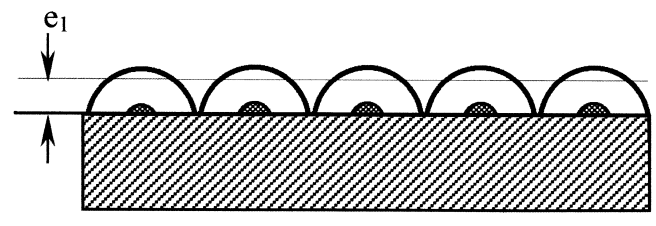

(a) $\quad \mathrm{T}_{1}$

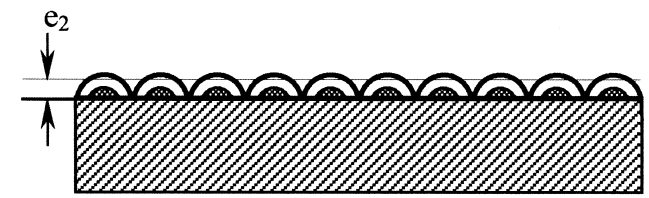

(b) $\quad T_{2}>T_{1}$

Figure 7. Illustrating how an increase in the nucleation rate with increasing temperature will cause a decrease in the average interfacial layer thickness e upon formation of a continuous layer.

discrepancy observed for the $\mathrm{Cu}-\mathrm{Cr} / \mathrm{C}_{\mathrm{V}}$ system between Eq. (1) and small-angle data in Ref. [5] is likely to be caused by a continuation of chemical reaction between the substrate and the liquid behind the triple line, causing diversion of solute diffusion lines away from the triple line and, in turn, slowed spreading. This diversion is important for the $\mathrm{Cu}-\mathrm{Cr} / \mathrm{C}_{\mathrm{v}}$ wetting couple for which diffusion through the reaction layer is faster, $\mathrm{D}_{\mathrm{C}}$ being one to two orders of magnitude higher [6,7], leading to final carbide layers several micrometers thick.

As the temperature is increased from 1020 to $1100^{\circ} \mathrm{C}$, the slope of the line through the data in Fig. 6 increases by a factor of 2.5 . At both 1020 and $1100^{\circ} \mathrm{C}, \mathrm{C}_{\mathrm{e}} \ll \mathrm{C}_{0}$, such that the variation in $\mathrm{C}_{0}-\mathrm{C}_{\mathrm{e}}$ is negligible in this temperature range; similarly, $\mathrm{n}_{\mathrm{V}}$ undergoes no significant change. The activation energy for diffusion of $\mathrm{Ti}$ in the molten alloy is at most $50 \mathrm{~kJ} \cdot \mathrm{mole}^{-1}$ [12]; hence, increasing the temperature from 1020 to $1100^{\circ} \mathrm{C}$ will cause an increase in the value of $\mathrm{D}$ by a factor 1.3 at most. Thus, the increased rate of spreading of the triple line as the temperature increases from 1020 to $1100^{\circ} \mathrm{C}$ is explained by Eq. (1) only if we admit that the thickness of reaction product at the triple line, e, decreases by a factor near 2 as the temperature increases by $80^{\circ} \mathrm{C}$. This, in turn, indicates that the reaction layer growth mechanism must undergo a significant change as the temperature is increased in this range; unfortunately this could not be checked due to destruction of the interface after cooling from $1100^{\circ} \mathrm{C}$. We note, however, that since e is the average thickness of the individual reaction product grains when a continuous layer is formed at the interface, such a decrease in e could be explained by an increase in the rate of nucleation of reaction product grains at the interface along the triple line. Indeed, the activation energy of nucleation is far higher than that of diffusion in the liquid, such that increasing the temperature from 1020 to $1100^{\circ} \mathrm{C}$ could cause a significant increase in the surface density of TiC grains along the interface, causing in turn a correspondingly high decrease in e as illustrated in Fig. 7.

\section{Conclusion}

- The addition of 3at.\% Ti to $\mathrm{Cu}-15 \mathrm{at} . \% \mathrm{Sn}$ leads to very good wetting on vitreous carbon, the final contact angle being close to $10^{\circ}$. This is due to the formation, at the interface, of a continuous layer of $\mathrm{TiC}$ of thickness slightly below $0.5 \mu \mathrm{m}$. Curves of the drop base radius versus time do not present a linear domain, indicating that spreading is not controlled by the local kinetics of interfacial reaction, but rather by diffusion of Ti from the drop bulk to the triple line.

- For contact angles lower than $90^{\circ}$, spreading kinetics of $\mathrm{Cu}-15 \mathrm{at} . \% \mathrm{Sn}-3 \mathrm{at} . \% \mathrm{Ti}$ on vitreous carbon agree fully with the analysis of Ref. [4]. This agreement is attributed to the impervious nature of the reaction layer behind the triple line.

- For contact angles above $90^{\circ}$, spreading kinetics of $\mathrm{Cu}-15 \mathrm{at} . \% \mathrm{Sn}-3$ at.\% Ti on vitreous carbon show the same enhancement in spreading rate as in $\mathrm{Cu}-\mathrm{Cr} / \mathrm{C}$ data of Ref. [5]. The causes of this enhancement will be analysed in a future publication. 


\section{References}

1. Y. V. Naidich, in Progress in Surface and Membrane Science, vol. 14, ed. D. A. Cadenhead and J. F. Danielli, p. 353, Academic Press, New York (1981).

2. R. Standing and M. Nicholas, J. Mater. Sci. 13, 1509 (1978).

3. K. Landry and N. Eustathopoulos, Acta Mater. 44, 3923 (1996).

4. A. Mortensen, B. Drevet, and N. Eustathopoulos, Scripta Mater. 36, 645 (1997).

5. R. Voitovitch, A. Mortensen, F. Hodaj, and N. Eustathopoulos, Acta Mater. 47, 1117 (1999).

6. F. J. J. van Loo and G. F. Bastin, Metall. Trans. 20A, 403 (1989).

7. W. Mayr, W. Lengauer, P. Ettmayer, D. Rafaya, J. Bauer, and M. Bohn, J. Phase Equilibria. $20(1), 35$ (1999).

8. Y. V. Naidich, V. N. Eremenko, V. V. Fesenko, M. I. Vasiliu, and L. F. Kirichenko, in The Role of Surface Phenomena in Metallurgy, ed. V. N. Eremenko, p. 41, Consultants Bureau, New York (1963).

9. N. Eustathopoulos, M. Nicholas, and B. Drevet, Wettability at High Temperatures, Pergamon Materials Series, p. 123, Pergamon Press, New York (1999).

10. O. Dezellus, Doctoral Thesis, Institut National Polytechnique de Grenoble, France (2000).

11. M. G. Nicholas, Br. Ceram. Trans. J. 85, 144 (1986).

12. G. H. Geiger and D. R. Poirier, Transport Phenomena in Metallurgy, p. 459, Addison-Wesley Publishing Company, Reading, MA (1980). 